18

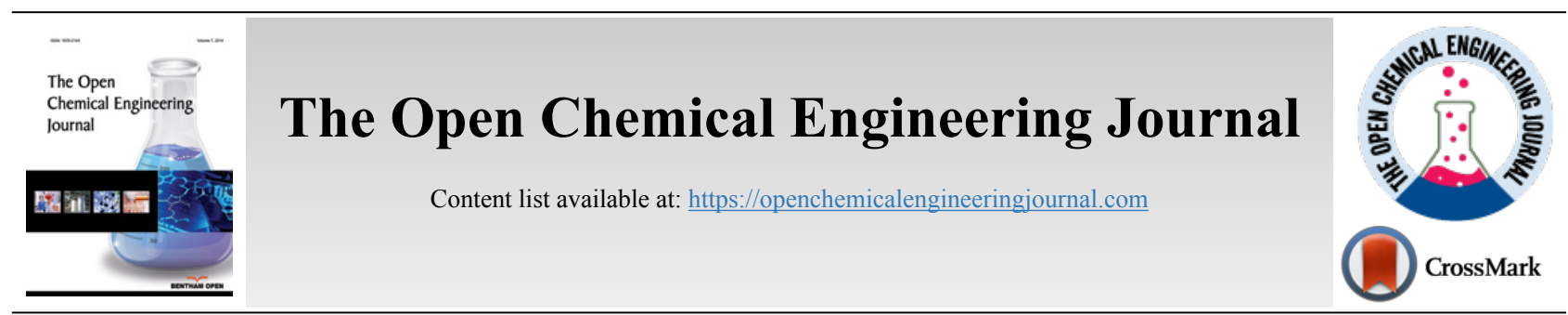

RESEARCH ARTICLE

\title{
Potential Evaluation of PVDF/PAN Membranes for Separation of Oil from Industrial Waste
}

\author{
Jigesh Mehta ${ }^{1, *}$, Deepak S. Panwar ${ }^{1}$, Anand Metre ${ }^{2}$ and Mathurkumar S. Bhakhar ${ }^{2}$ \\ ${ }^{1}$ Department of Chemical Engineering, Mass Transfer Laboratory, School of Engineering, P P Savani University, Kosmaba - 394125, Surat, Gujarat, \\ India \\ ${ }^{2}$ Department of Chemical Engineering, G H Patel College of Engineering \& Technology, Vallabh Vidyanagar, Anand - 388120, Gujarat, India
}

\begin{abstract}
:
Aim:

The aim of the experiment is to characterize the Modified Membrane from PVDF/PAN and its application in removing the Emulsified oil waste from the Industry.

Objective:

To get the maximum separation of the emulsified oil from the waste water, composite (PVDF/PAN) membrane was prepared in the laboratory.

Methods:

New PVDF/PAN blend based ultrafiltration membranes were synthesized by phase inversion method. The blend membrane was treated at room temperature with aqueous sodium hydroxide solutions.

Results:

The facile eco-friendly preparation of PVDF/PAN blended membrane has a wide potential for practical applications in emulsified wastewater remediation. The chemical functionality of the modified membranes was confirmed by IR spectra.

\section{Conclusion:}

For the separation of emulsified oily wastewater, the as-prepared composite (PVDF/PAN) membrane could effectively separate oil/ water emulsions with separation efficiency of above $99.8 \%$. Unmodified membranes (A and B) showed 95.4-99.8\% rejection. However, in the case of membranes $\mathrm{C}$ and $\mathrm{D}$, oil rejection was higher for the modified membranes as compared to the unmodified membranes.
\end{abstract}

Keywords: Polyacrylonitrile (PAN), Polyvinylidenefluoride (PVDF), Ultrafiltration, Hydrophilicity, Emulsified oily wastewater, Adsorption.

\begin{tabular}{|l|l|l|l|}
\hline Article History & Received: February 18, 2021 & Revised: April 13, 2021 & Accepted: June 02, 2021 \\
\hline
\end{tabular}

\section{INTRODUCTION}

With the increasing development of petrochemical industries, a huge amount of oily wastewater has been produced from oil spilling or unavoidable emission, causing major harm to the ecosystem and human health [1 - 4]. Traditional separation methods like oil skimmers, centrifugation, adsorption and coalesces have been applied for oily wastewater purification [5 - 7]. However, most of the processes are high cost and low efficiency to separate oil/water

* Address correspondence to this author at the 1Department of Chemical Engineering, Mass Transfer Laboratory, School of Engineering, P P Savani University, Kosmaba - 394125, Surat, Gujarat, India; Tel: 08460436750;

E-mail: jigesh.mehta@ppsu.ac.in mixture with oil droplet size less than $20 \mu \mathrm{m}$ size [8]. Thus, literature survey regards as membrane separation process as an attractive separation technology due to low energy consumption, environmentally friendly, high separation efficiency, etc [9 - 12]. Microfiltration (MF), Ultrafiltration (UF), Nanofiltration (NF) and Reverse Osmosis (RO) are wellknown pressure-driven membrane processes. Ultrafiltration membrane separation processes are recent tread technique accepted worldwide with no requirement of chemical reagents for the treatment, no oil content in filtrate water, compact and fully automated system. Various polymeric materials such as Cellulose Acetate (CA) [13], Polyacrylonitrile (PAN) [14], Polyvinylidene Fluoride (PVDF) [15, 16], Polyethersulfone (PES) [17], Poly(pphenylene sulfide) (PPS) [18] and Poly- 
sulfone (PSF) [19] have been widely used to prepare membranes for oil/water emulsion separations. Owing to high mechanical strength, good chemical stability and toughness, PVDF and PAN have been recognized as one of the suitable choices for the separation of oil/water emulsions [20 - 25]. This article focuses on preparation of PVDF/PAN blend ultrafiltration membranes of different compositions according to phase inversion process with alkali solution modification at room temperature. Characterization of the membranes by contact angle measurement, Attenuated Total Reflectance Infra-red (ATR-IR) and atomic force microscope (AFM) were performed and measurement of the pure water flux (PWF) at different operating pressures and \% rejection of emulsion wastewater were also studied.

\section{METHODS}

\subsection{Materials \& Chemicals}

Polyvinylidene fluoride (PVDF) and Polyacrylonitrile (PAN) powder was purchased from Solvay Solexis, France and Aldrich Chemicals (USA), respectively. Solvent N-methyl-2pyrrolidinone (NMP - 98\%) and Acetone (99\%) were purchased from Spectrochem Pvt Ltd, India and Ranbaxy fine chemicals ltd, New Delhi, India, respectively. Sodium Hydroxide $(\mathrm{NaOH}-99.9 \%)$ powder was purchased from Ranbaxy fine chemicals ltd, New Delhi, India. For the experimental analysis, hydraulic oil was purchased from Servo Hydraulic oil centre (IOCL), Bandra (EAST), Mumbai, India.

\subsection{Membrane Casting Process}

Ultrafiltration membranes were prepared from NMP solution of PVDF and PAN blends on a non-woven polyester fabric (H 2564) according to phase inversion method using motor driven continuous prototype membrane casting machine as shown schematically in Fig. (1) (Schematic diagram). The freshly casted polymer film on the fabric supports was gelled at $21-25{ }^{\circ} \mathrm{C}$ in water bath containing deionized water [26, 27]. Casting thickness of membranes was fixed at $160 \mu \mathrm{m}$ by using micrometers attached to the casting blade. The relative humidity of the polymer chamber was maintained at around $58 \%$ using dehumidifier air. Casted membranes were allowed in gelation bath for an hour and then preserved in deionized water until testing. The thicknesses of the membranes were measured with micrometer at different places. The membranes were characterized for pure water permeation rate and for the separation of oil-water emulsion.

\subsection{Membrane Characterization}

The morphology of prepared membranes was characterized by Attenuated Total Reflectance Infra-red (ATR-IR) (SICHART, VallabhVidyanagar, Anand, India) and Atomic force microscope (AFM) (SICHART, VallabhVidyanagar, Anand, India). Contact angles (CAs) of membrane were detected for chemical composition and surface hydrophilicity by a contact angle goniometer (CSM-CRI Laboratory, Bhavnagar, India). Systematic performance studies were conducted in different operating conditions such as variations in feed concentration, feed solution and Operating pressure.

\subsection{Oil/Water Emulsions Preparation}

The oil/water emulsion was prepared by taking organic solvent such as petroleum ether and toluene which was dispersed into deionized water by stirring for $60 \mathrm{~min}$, and then the oil/ water emulsion was obtained. Besides, the surfactantstabilized oil/water emulsions were also prepared. Firstly, surfactant-free emulsions including petroleum ether and toluene were prepared; then, $10 \mathrm{mg}$ of Tween- 80 as emulsifying agent was added into the above solutions by stirring for $12 \mathrm{~h}$. All the surfactant-stabilized oil/water emulsions were stable for several months until there was no precipitation observed.

\subsection{Separation Phenomena of Oil/Water Emulsion}

The permino experimental setup (NF/UF/RO) supplied by perminonics membrane private limited, Vadodara, India is shown in Fig. (2). It consists of a flat sheet module inbuilt as well as a hollow fibre and tubular module. The test cell, made of stainless steel (dimension: $200 \times 100 \times 40 \mathrm{~mm}^{3}$ ) and inner dimension of the test cell was $150 \mathrm{~mm} \times 100 \mathrm{~mm} \times 2 \mathrm{~mm}$. Stainless steel gauge of 250 mesh size was kept on which 1 $\mathrm{mm}$ stainless steel plate was profound. The whole membrane assemble was covered with filter paper and blended prepared membrane was installed. Strength in terms of mechanical operation can be enriched using such installation of membrane material. Variable frequency drive (VFD) to control the feed flow, pressure gauge (both inlet and outlet stream) and high pressure switch (HPS) having trip shut down limit kept as 15 $\mathrm{kg} / \mathrm{cm} 2$ (Maximum limit of pressure is $40 \mathrm{~kg} / \mathrm{cm} 2$ ) as safety point are the major parts to the set-up. Emulsified oil/water Feed solution from the feed tank (5 litre maximum capacity) was pressurized by high pressure pump and allowed to flow

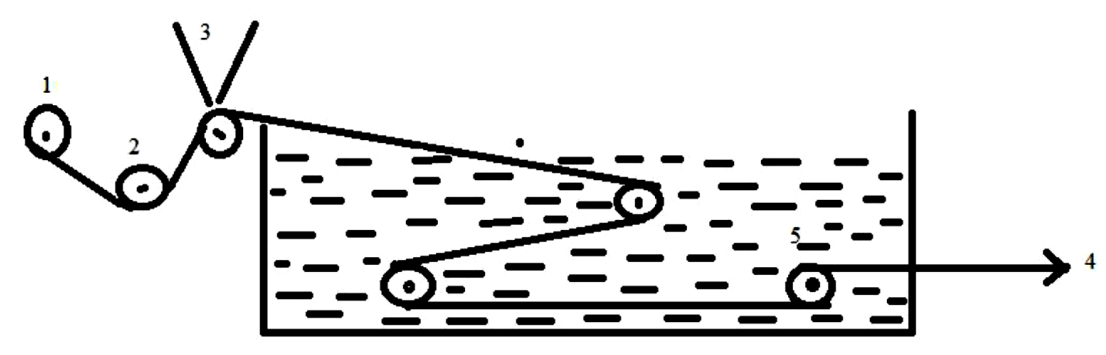

Fig. (1). Schematic Diagram of the PVDF/PAN Blending membrane

(1. Fabric supply roller, 2.Guiding rollers, 3.Polymer solution, 4.Water gelation Bath, 5. Membrane Winding). 


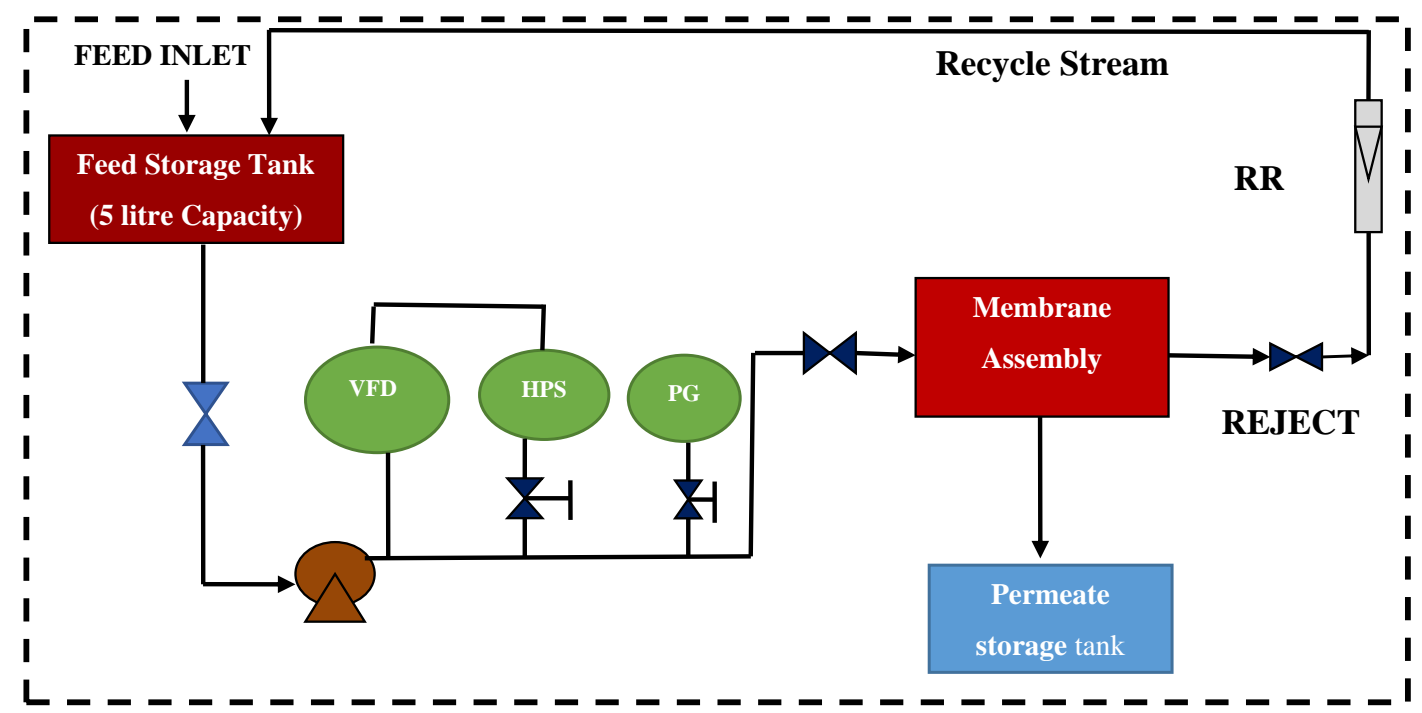

Fig (2). Permino Schematic diagram of Membrane separation Unit (Membrane Technology Laboratory, P P Savani University)

VFD: Variable Frequency Device; HPS: High Pressure Switch, Shut down pressure in case of emergency is 15 kg/cm2; PG: Pressure Gauge; RR: Reject Rotameter.

into the test cell. Reject stream from the membrane assembly was collected back and recycled to the feed tank using rotameter. After each filtration, the blend membrane was washed with ethanol and deionized water. The flux of membranes is calculated by the following equation:

$$
\begin{gathered}
J=\frac{V}{A x t} \\
\operatorname{FRR}(\%)=\frac{J_{w t}}{J_{w o}} x 100
\end{gathered}
$$

Where, where $\mathrm{V}(\mathrm{L})$ is the volume of permeate flow, A $\left(\mathrm{m}^{2}\right)$ is the effective area of filter, $\mathrm{t}(\mathrm{h})$ is the filtration time. The separation efficiency ( $\mathrm{R} \%$ ) of membranes was evaluated by measuring the total organic carbon of oil/water emulsion.

The flux recovery rate (FRR) of membranes is calculated by the following equation:

Where, $\mathrm{J}_{\mathrm{w} 0}$ is the pure water flux before filter oil/ water emulsion, $J_{\mathrm{wt}}$ is the pure water flux after oil/ water emulsion separation experiment.

\section{RESULTS AND DISCUSSION}

\subsection{Membrane Preparation \& Modification}

Polyvinylidene fluoride (PVDF) - polyacrylonitrile (PAN) blends membrane of different composition was prepared in Nmethyl-2-pyrrolidone (NMP) solution according to phase inversion method. Water containing $0.1 \%$ SLS was used as the gelation medium. The preparation conditions and the characteristics of the membranes are presented in Tables $\mathbf{1}$ and 2. The amount of PVDF, PAN and PVP was varied from 10 to $14 \%, 2$ to $4 \%$ and $2 \%$, respectively while keeping the total amount (PVDF + PAN + PVP) polymers as 16 to $20 \%$.
Modification of blend membranes was performed by treating $2 \%$ aqueous alkaline solution $(\mathrm{NaOH})$ for 2 hours at room temperature. Depending on the reaction chemistry that occur between nitrile (-CN) groups and sodium hydroxide, 16, 18 and $20 \%$ modified membranes were prepared. Solubility of $\mathrm{NaOH}$ treated PVDF/PAN blend was tested in polar aprotic solvents. It was observed that the PVDF/PAN blend membrane treated with less than $0.5 \mathrm{~N} \mathrm{NaOH}$ was soluble in NMP and other aprotic solvents while PVDF/PAN treated with $0.5 \mathrm{~N}$ and higher concentration of $\mathrm{NaOH}$ was insoluble in NMP in which it was freely soluble before the treatment. This clearly indicates the formation of hydrophilic functional groups like $-\mathrm{COOH}$ and $-\mathrm{CONH}_{2}$, which resist the dissolution of modified PVDF/PAN blend membrane in an aprotic solvent.

\subsection{Membrane Pure Water Flux}

Pure Water Flux (PWF) is a preliminary parameter for the UF membranes. Generally, PWF is strongly dependent on membrane morphology such as thickness of the membrane, Pore Size Distribution (PSD) and porosity of the top skin layer, which in turn reflects the effects of membrane preparation conditions like casting dope composition (concentration of the polymer, types of additives, solvents), as-cast thickness, gelation medium, etc. The Pure Water Fluxes (PWF) of membranes exponentially decrease with an increase in the polymer composition in casting solution when total polymer composition was $16 \%, 18 \% \& 20 \%$. The PWF was decreased on increasing the polymer (PVDF+PAN) concentration from 16 to $20 \%$ in the dope solution in NMP which clearly reveals the influence on pore size and porosity of the membrane by polymer content. The effect of different membranes prepared with code v/s pure water permeability is indicated in Fig. (3). 


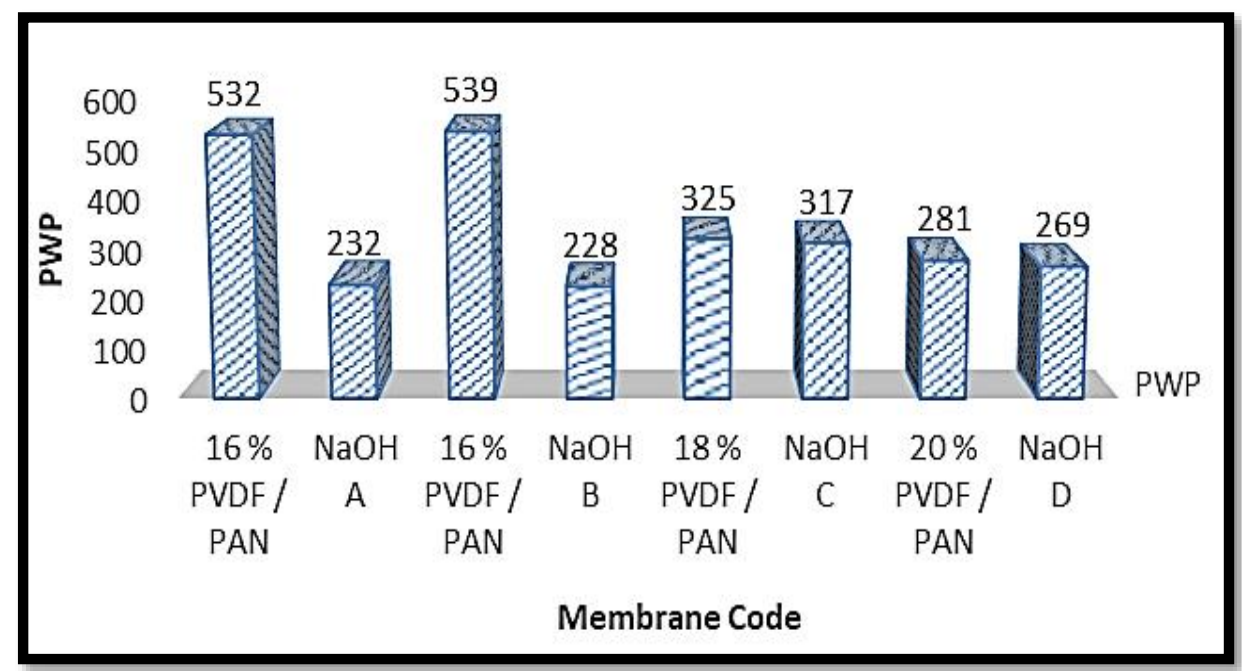

Fig (3). Effect of PVDF/PAN blend membrane on PWP.

\subsection{Morphology Study of PVDF/PAN Blend Membrane}

\subsubsection{Surface Hydrophilicity}

Generally, relative hydrophilicity of surface can be qualitatively determined by measuring contact angle of water droplets. The contact angle measurement of the membranes determined by the instrument shown in Fig. (4). The hydrophilic nature of membranes surface increases with \% PAN increase in polymer solution. However, contact angles of the membranes prepared using $18 \% \& 20 \%$ total polymer solution are comparatively higher than those of the membranes made of $16 \%$ total polymer, for the same concentration of PVP. Thus, contact angle values depend on surface chemistry, porosity and surface roughness and heterogeneity. The lower contact angle for membrane A \& B is due to PVP impregnation at the top layer of the casting solution layer during membrane formation (before entering into the gelation bath). This results in the formation of a very thin skin layer of PVP along with PVDF-PAN blend support. Since PVP is soluble in water, it leaches out during phase inversion process and thus creates a membrane with higher porosity and higher roughness. The increase in surface porosity and roughness usually causes a decrease in the contact angle of the membrane surface. This clearly indicates that the $\mathrm{NaOH}$ treatment imparts hydrophilic characteristics to the membrane surface due to the formation of the carboxylic acid group and amide functional groups. The structure of modified and unmodified membranes was confirmed by IR spectra. Results showing some new peaks at 1743 and $1662 \mathrm{~cm}^{-1}$, which are apparently assigned to carbonyl stretching of carboxylic acid and amide group respectively, due to the arise of hydrolysis of nitrile $(\mathrm{CN})$ group during treatment with $\mathrm{NaOH}$ solution.

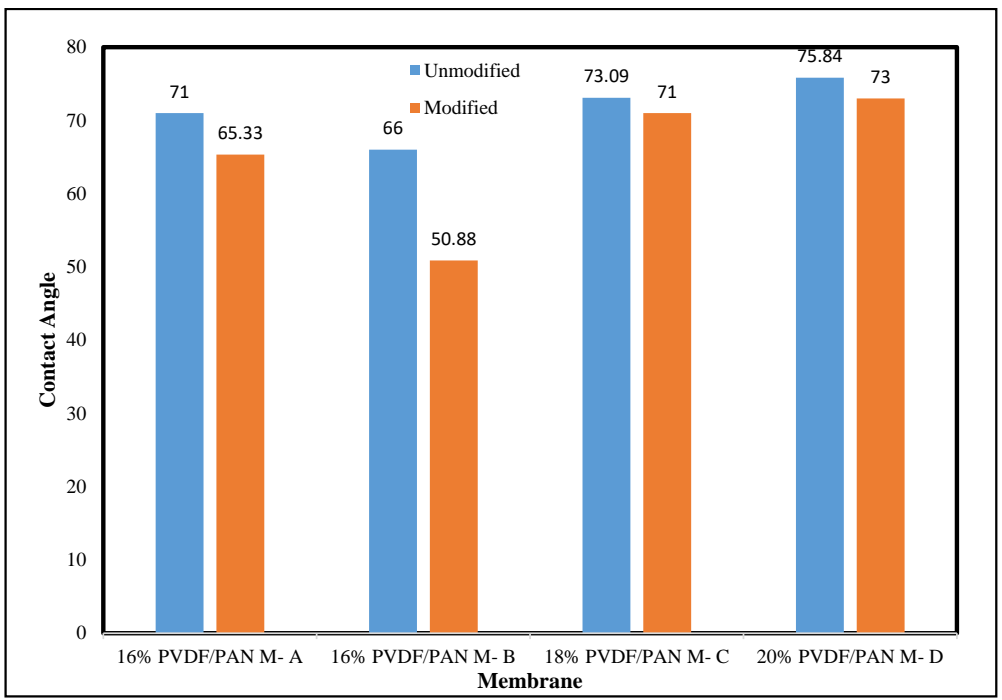

Fig. (4). Contact Angle of PVDF/PAN blend membrane 
Table 1. Preparation method of PVDF-PAN blend membranes.

\begin{tabular}{|c|c|c|c|c|c|}
\hline Membrane Code & \% PVDF & \% PAN & \% PVP & \% NMP & $\begin{array}{c}\text { Total Polymer } \\
\text { Concentration }\end{array}$ \\
\hline Membrane A & 10 & 4 & 2 & 84 & 16 \\
\hline Membrane B & 12 & 2 & 2 & 84 & 16 \\
\hline Membrane C & 14 & 2 & 2 & 82 & 18 \\
\hline Membrane D & 14 & 4 & 2 & 80 & 20 \\
\hline
\end{tabular}

Gelation Bath: Room Temp. (29॰C) deionized water; RH: 48\%; Bath temp: $20 \circ \mathrm{C}$.

Table 2. Characteristics of membranes.

\begin{tabular}{|c|c|c|}
\hline Membrane Code & Thickness $(\boldsymbol{\mu m})$ & PWP $(\mathbf{L M H})$ \\
\hline Membrane A & 250 & 532 \\
\hline Membrane B & 270 & 539 \\
\hline Membrane C & 220 & 325 \\
\hline Membrane D & 240 & 281 \\
\hline NaOH A & 260 & 232 \\
\hline NaOH B & 280 & 228 \\
\hline NaOH C & 240 & 317 \\
\hline NaOH D & 260 & \\
\hline
\end{tabular}

\subsubsection{Attenuated Total Reflectance Infra-red (ATR-IR)}

The ATR-IR spectra of PAN/PVDF blend membranes before and after hydrolysis of sodium hydroxide $(\mathrm{NaOH})$ are shown in Figs. (5-8). The nature of the functional groups present on the top surface of membranes was identified by Attenuated Total Reflectance infra-red (ATR-IR) spectroscopic technique. PVDF showed peaks at $1000-1400 \mathrm{~cm}^{-1}$ and PAN showed peaks at $2240-2260 \mathrm{~cm}^{-1}$. The bands for modified membranes occurred at $1300-1800 \mathrm{~cm}^{-1}$ due to hydrolysis. Figs. (5 and 6) show that the FT-IR subtraction spectra of the substances on the membrane surface before and after hydrolysis of the $16 \%$ PAN/PVDF blends ultrafiltration membrane. In the spectra, the peaks at $2256 \mathrm{~cm}^{-1}$ were attributed to absorption by nitrile groups, which is the characteristic absorption of PAN. The bands near $1089 \mathrm{~cm}^{-1}$, $1199 \mathrm{~cm}^{-1}$ and $1292 \mathrm{~cm}^{-1}$ are assigned to $-\mathrm{CF}_{2}$ groups in PVDF. Figs. (7 and 8) show the ATR-IR subtraction spectra of the substances on the membrane surface before and after hydrolysis of the $18 \%$ and $20 \%$ PAN/PVDF blends ultrafiltration membrane, respectively. In the spectra, the peaks at $2258 \mathrm{~cm}^{-1}$ were attributed to the absorption by nitrile groups, which is the characteristics absorption of PAN and appears in each spectrum. The bands near $1076 \mathrm{~cm}^{-1}, 1184 \mathrm{~cm}^{-1}$ and 1280 $\mathrm{cm}^{-1}$ are assigned to the $-\mathrm{CF}_{2}$ groups in PVDF.

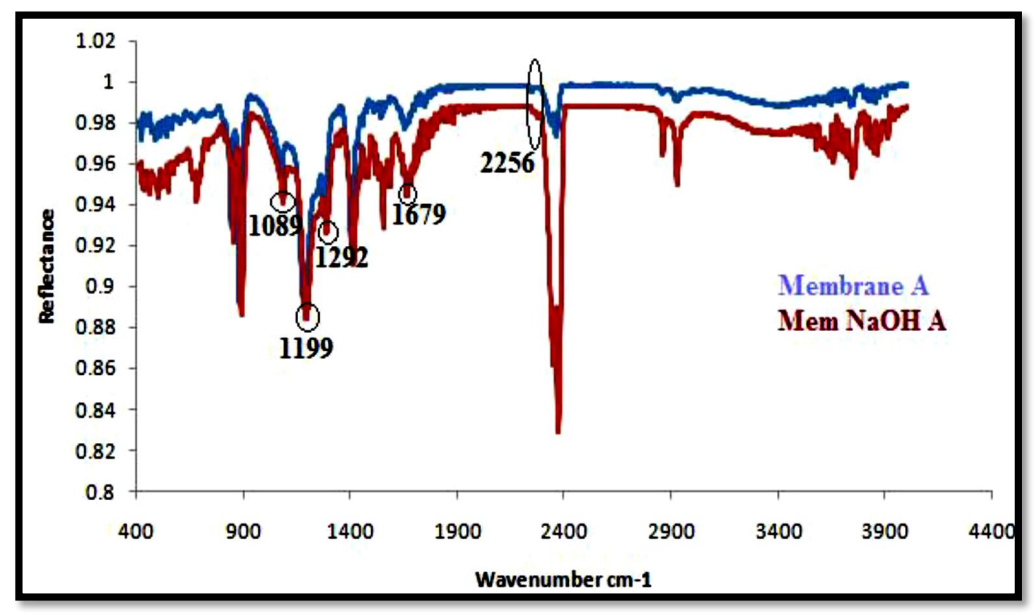

Fig. (5). IR spectra of unmodified and modified membrane A. 


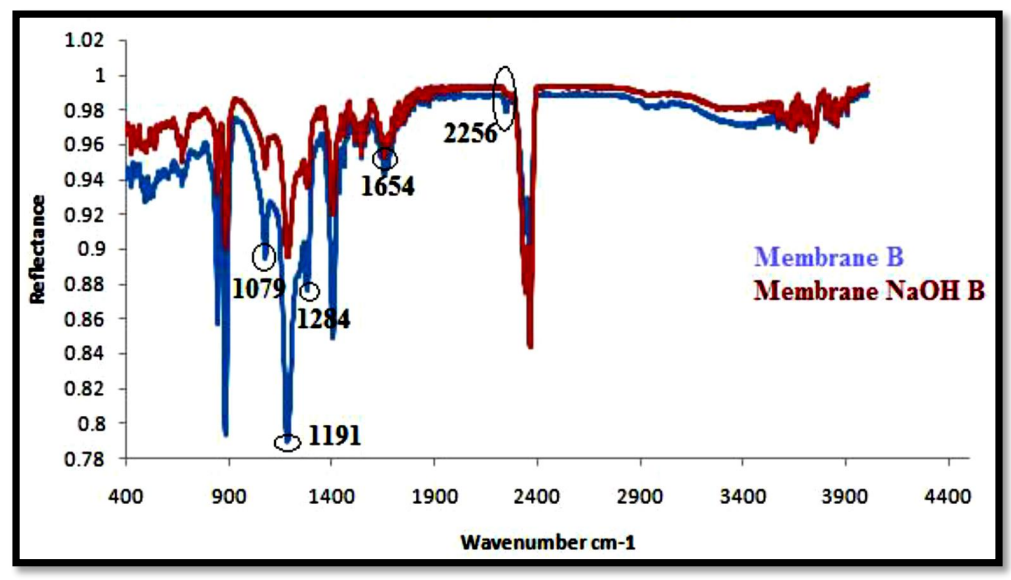

Fig (6). IR spectra of unmodified and modified membrane B.

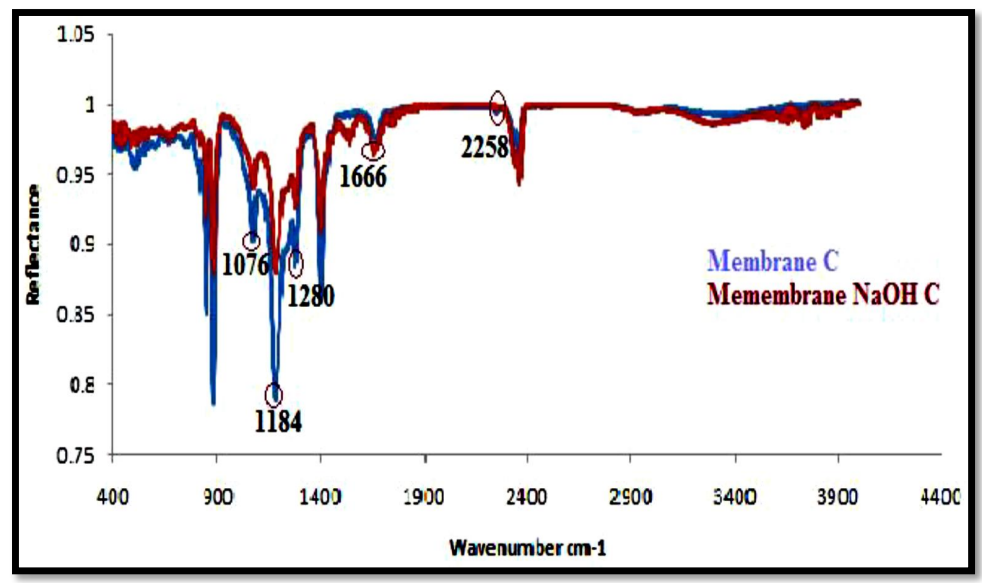

Fig. (7). IR spectra of unmodified and modified membrane D.

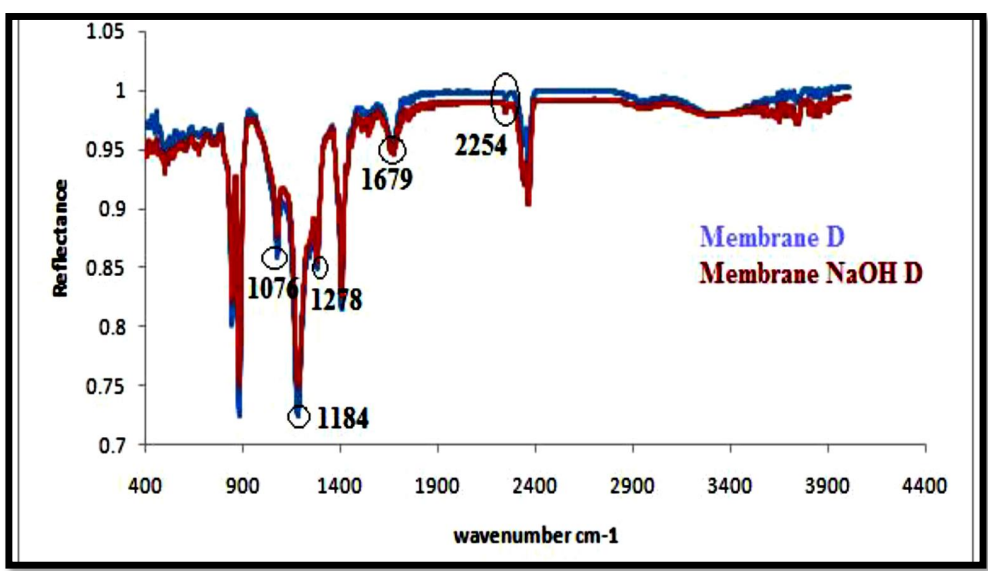

Fig. (8). IR spectra of unmodified and modified membrane D. 


\subsubsection{Atomic Force Microscopy (AFM)}

Figs. (9 and 10) show the AFM images of the blend membranes with sodium hydroxide $(\mathrm{NaOH})$. Membrane surface morphology can be studied by measuring the surface roughness using high-resolution windows based NT -MDT surface analysis software, as shown in Table 3. It reports different structural sizes on the membrane surface and clearly indicates that the membrane average surface roughness was affected by alkali treatment. On the basis of the value of average roughness $(\mathrm{Ra})$, we concluded that the roughness of the membrane surfaces increased with increasing $\mathrm{NaOH}$ contents. On the one hand, this resulted from the aggregation of $\mathrm{NaOH}$ particles on the membrane surface, and on the other hand, the craters on the membrane surface help to increase the roughness of the membrane. However, we expected that the surface of membranes could be as smooth as possible to achieve good hydrophilicity. In addition, the hybrid membrane exhibited a slightly higher roughness, but the hydrophilicity of membranes was enhanced by the presence of $\mathrm{NaOH}$. Alkali treatment causes the hydrolysis of the hydrophobic nitrile group to a more hydrophilic carboxylic group.
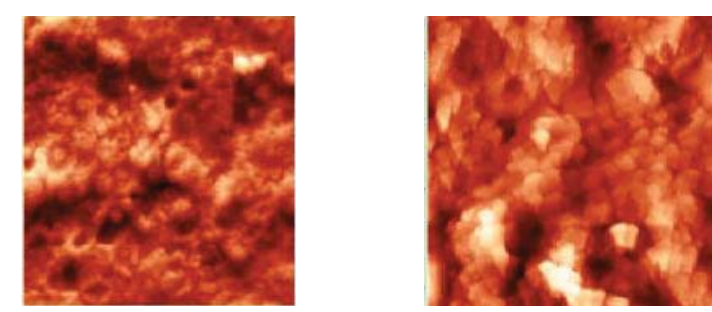

(a)
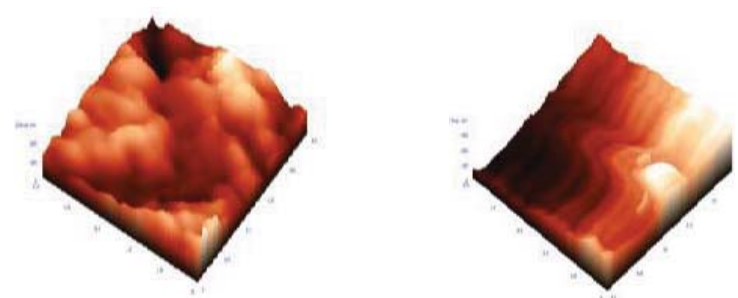

(b)

Fig. (9). Schematic diagram of (a) Membrane A and B (b) NaOH Treated membrane A \& B.
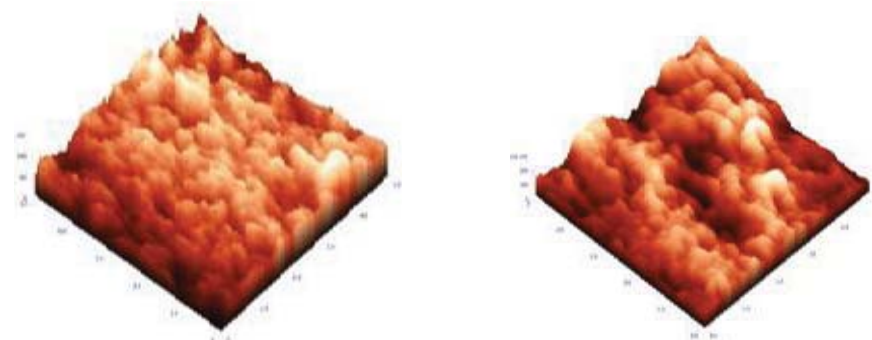

(a)
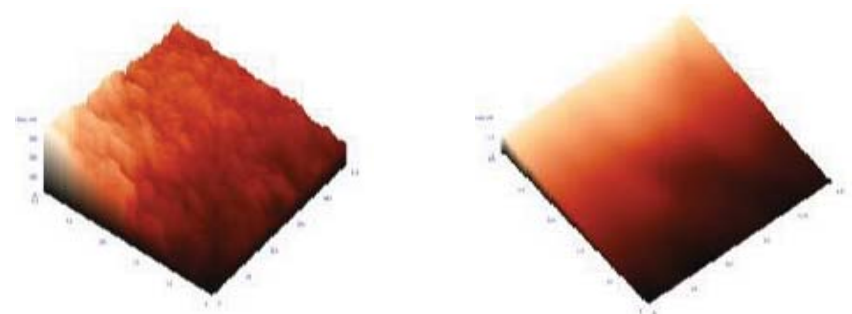

(b)

Fig (10). Schematic diagram of (a) Membrane $\mathrm{C}$ and $\mathrm{D}$ (b) NaOH Treated membrane C \& D. 
Table 3. AFM analysis

\begin{tabular}{|c|c|}
\hline Membranes & Average Roughness $\left(\mathbf{R}_{\mathbf{a}}\right)$ \\
\hline Membrane A & 22.00 \\
\hline Membrane B & 13.30 \\
\hline Membrane C & 20.46 \\
\hline Membrane D & 30.80 \\
\hline $\mathrm{NaOH}$ treated Mem-A & 32.84 \\
\hline $\mathrm{NaOH}$ treated Mem $-\mathrm{B}$ & 29.90 \\
\hline $\mathrm{NaOH}$ treated Mem-C & 21.12 \\
\hline $\mathrm{NaOH}$ treated Mem-D & 26.32 \\
\hline
\end{tabular}

\subsection{Effect of Operating Pressure}

\subsubsection{Pure Water Flux Membrane A \& B}

Pure water flux of membranes A and B as a function of operating pressure is plotted in Fig. (11). In general, pure water flux is directly proportional to the operating pressure. An increase in pure water flux was observed in the case of membranes $\mathrm{A}$ and $\mathrm{B}$ with the increased operation pressure in the range of 0-3 bar. Pure water flux obtained for membrane B is slightly higher than membrane A. After modification with sodium hydroxide, the PWF is decreased as compared to unmodified blend UF membrane. Immersing the membrane in alkali solution indicates the color changes. Light-yellowish to reddish-brown color appeared, which did not disappear during the entire period of alkali treatment. The appearance of reddish brown color confirmed the formation of cyclic $-\mathrm{C}=\mathrm{N}-$ conjugated naphthyridine structures in the PAN, which was verified by UV, IR and ESR techniques. Analytically proved results suggested that some significant changes in the membrane porous structure have occurred while it is treated with alkali solution. Similar results for membranes C and D are depicted in Fig. (12).

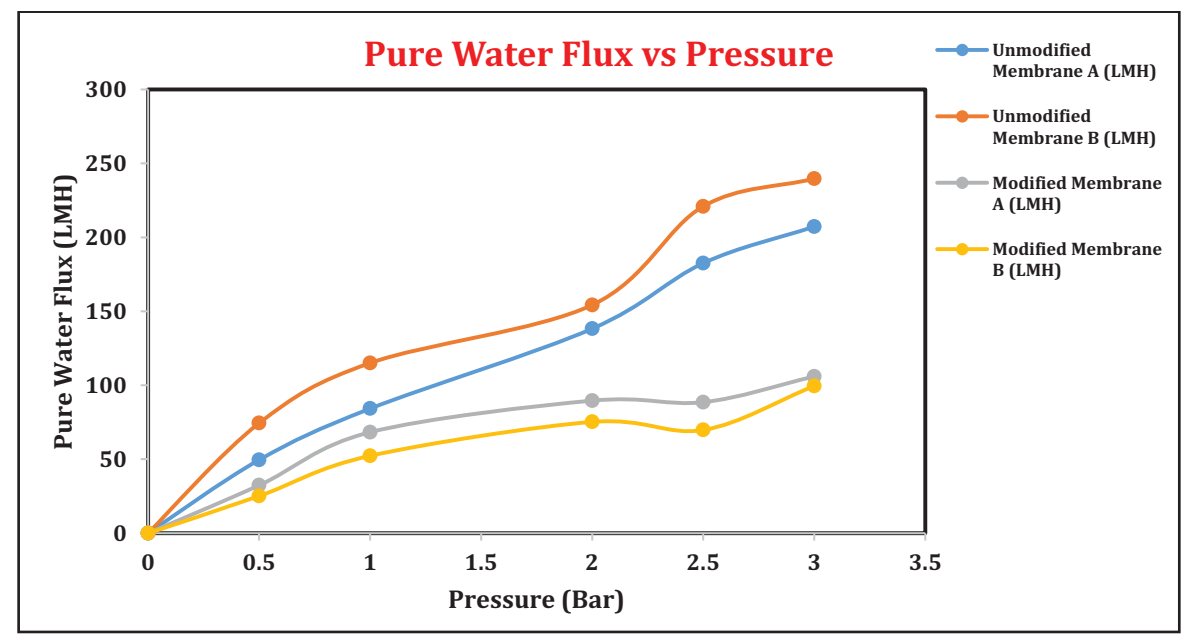

Fig. (11). Pressure vs. Pure water flux (A \& B).

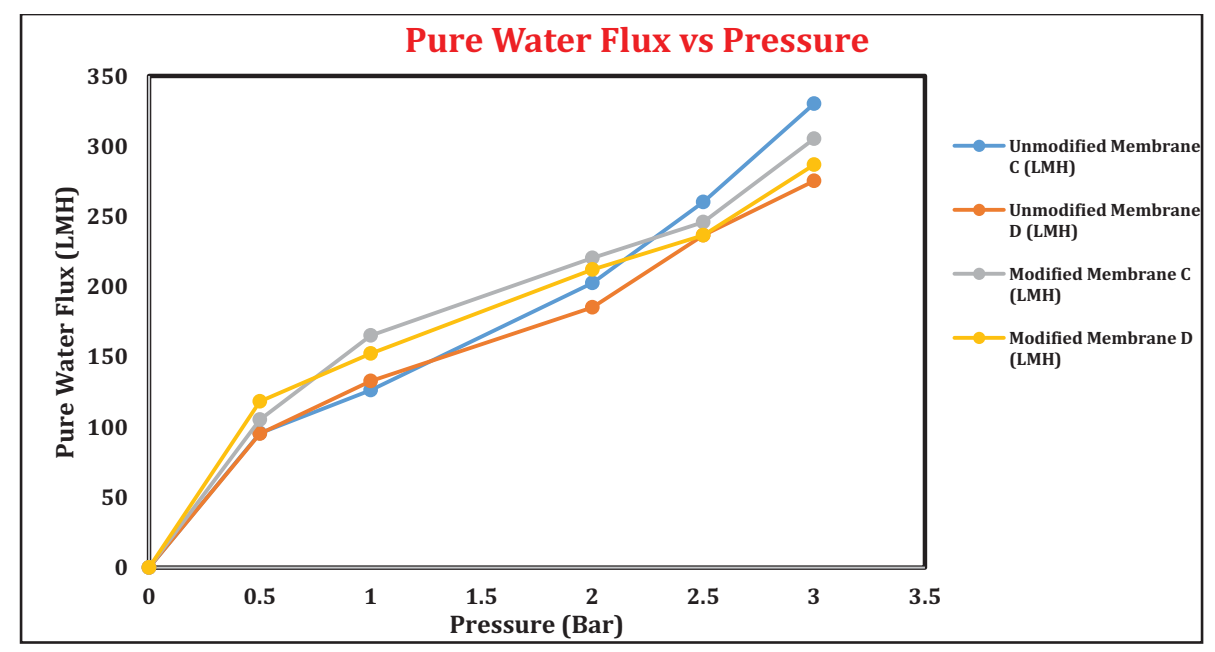

Fig (12). Pressure vs Pure water flux (C \& D). 


\subsubsection{Effect of Operating Pressure on Oil-in-Water Emulsion}

Major pollutants to the aquatic environment are the oilwater emulsion and hence, separation to be carried out only through tailor made membranes. Emulsion flux was increased with increase in pressure from 0 to 3 bars. Maximum flux value was obtained for unmodified membranes compared to modified membranes, which is similar to the trend in pure water flux. However, \% oil rejection of unmodified membranes was lower than the modified membranes. Fig. (13) shows that the emulsion flux of unmodified and modified membranes was increased with increasing pressure at 0 to 3 bars. The flux at 3 bars pressure for membrane $\mathrm{A}$ and membrane $\mathrm{B}$ was found to be 192.42 LMH and 256.45 LMH, respectively. For the modified membranes, the fluxes were 116.42 LMH and 150.96 LMH for membranes A and B, respectively. Flux value was decreased with alkali treatment of the membranes and also witnessed the conversion of nitrile group to cyclic naphthyridine and amide.

\subsection{3\% Rejection of Oil for Unmodified and Modified Membrane}

The $\%$ rejection was increased for unmodified and modified membranes with the increase in applied pressure from 0 to 3 bars. Unmodified membranes have given maximum oil rejection compared to modified membrane A and membrane $\mathrm{B}$. The data indicate that oil rejection was in the range of $95.4-99.8 \%$ for the unmodified membranes, whereas the oil rejection was $14-70 \%$ for the modified membranes. Further, the rejection also increased with an increase in applied pressure. This attributed to the fact that the increase in applied pressure causes a net increase in driving force and an increase in permeate flux without affecting the solute transport through the membrane. The net increase in water flux naturally results in the increase in solute rejection, as discussed in Figs. (14 and 15).

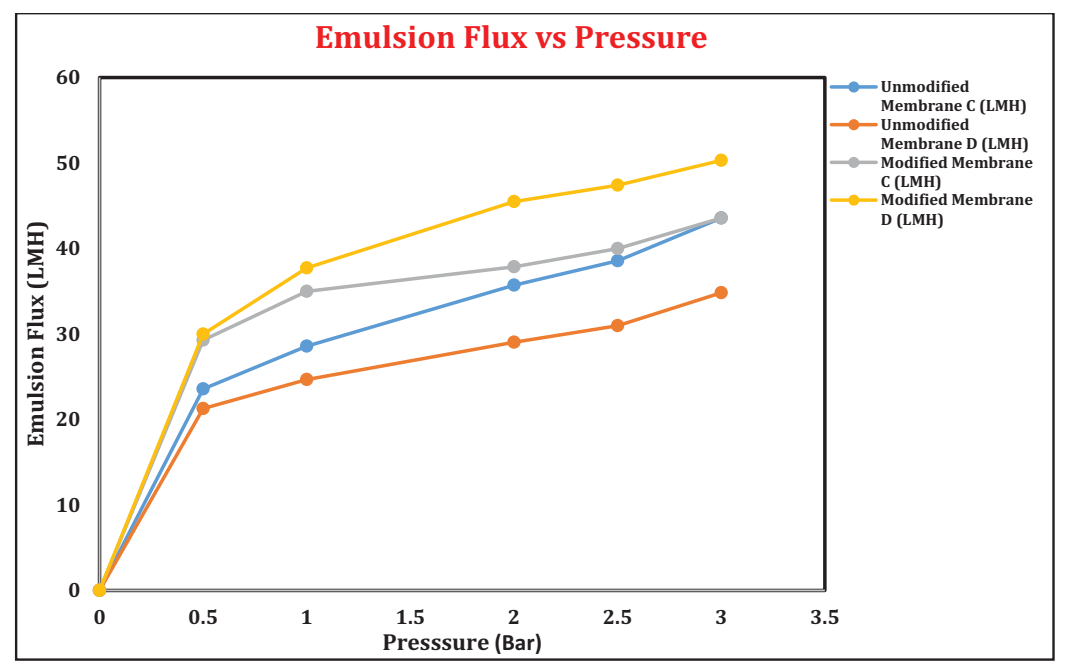

Fig. (13). Pressure vs. Emulsion Flux (C \& D).

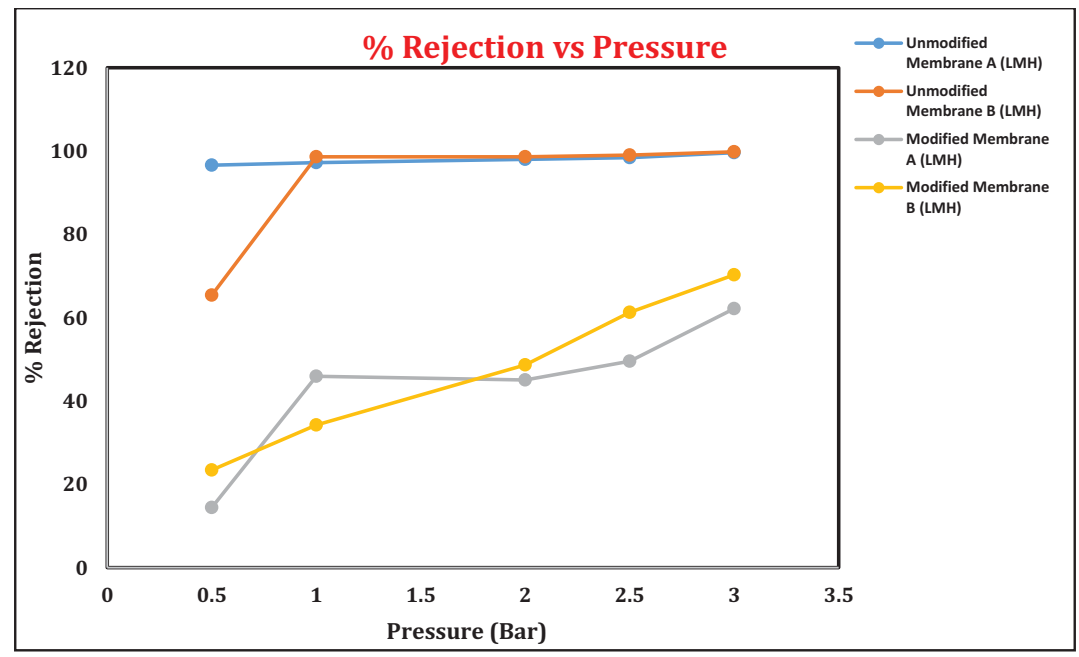

Fig (14). \% Oil rejection of unmodified \& modified membrane (A \& B). 


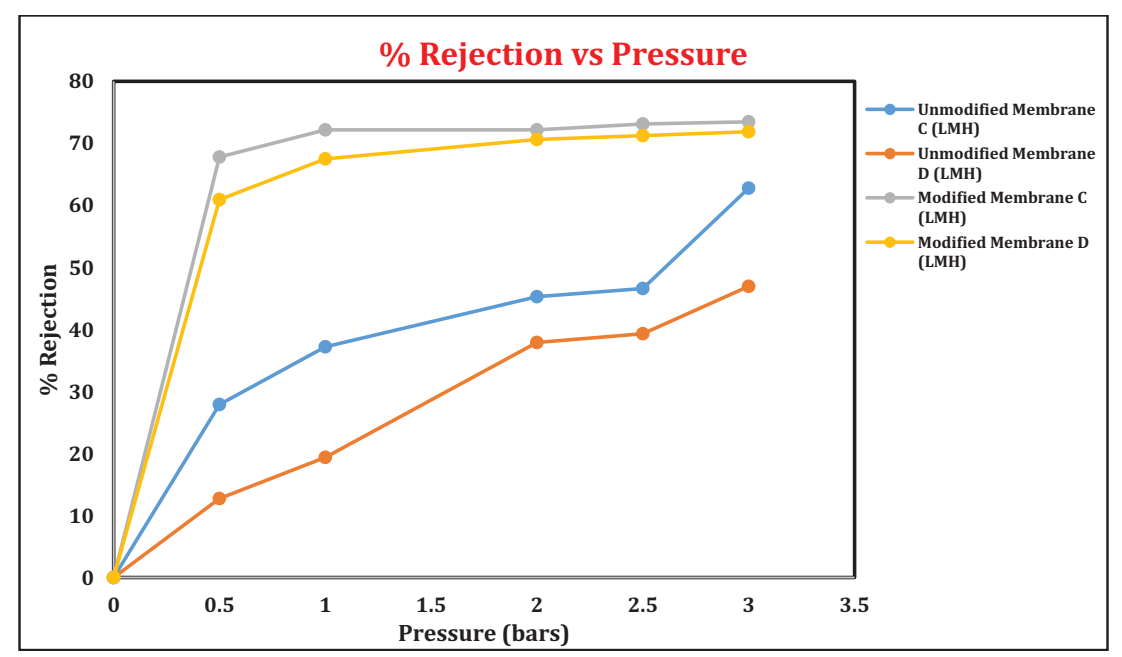

Fig (15). Performance of oil rejection of unmodified \& modified membrane (C \& D).

\subsubsection{Fourier Transform Infrared Spectroscopy}

The unmodified membrane structure is seen in Fig. (16) For the modified membrane, the changes in the structure of the membrane due to the effects of the $\mathrm{NaOH}$ are shown in Fig. (17). Table 4 indicates the intensity of light passing during the spectroscopy may be weak, medium or strong intensity representing the strength of the various bonds present. The unmodified membrane shows $\mathrm{C}-\mathrm{N}$ vibrations of aromatic compounds and $\mathrm{O}-\mathrm{H}$ bending and $\mathrm{C}-\mathrm{H}$ stretching vibrations of tertiary alcohols and phenols. These disappear in the modified membrane sample. This is due to interactions with $\mathrm{NaOH}$. Similarly, C-F stretching vibrations are also found to disappear in the modified membrane. The presence of $\mathrm{C}-\mathrm{H}$ stretching due to alkane is seen for the modified membrane sample, which may have appeared due to reactions with the $\mathrm{NaOH}$. Stretching vibrations of $\mathrm{C}-\mathrm{Cl}$ halogen compounds are also seen in the modified membrane sample but were not present in the unmodified sample.

\section{Table 4. FTIR analysis in tabular form.}

\begin{tabular}{|c|c|c|}
\hline Wave Number $\left(\mathbf{c m}^{-1}\right)$ & Intensity & Assignment \\
\hline 3439 & $\mathrm{M}$ & $\mathrm{N}-\mathrm{H}$ Stretching vibrations, secondary free; one band in Amines. \\
\hline 1585 & $\mathrm{~W}$ & Unsaturated nitrogen compounds -N=N- stretching vibrations, azo compounds, Secondary N-H bending vibrations. \\
\hline 1384 & $\mathrm{~S}$ & Alkane, gem-dimethyl, Halogen compounds, C-F stretching vibrations \\
\hline 1364 & $\mathrm{~S}$ & Alkane, tert-butyl, Halogen compounds, C-F stretching vibrations \\
\hline 1171,1104 & $\mathrm{~S}$ & Sulphur compounds C=S stretching vibrations \\
\hline 606 & $\mathrm{~S}$ & Halogen compounds, C-Cl stretching vibrations \\
\hline
\end{tabular}

$\mathrm{S}=$ strong intensity, $\mathrm{M}=$ medium intensity, $\mathrm{W}=$ weak intensity.

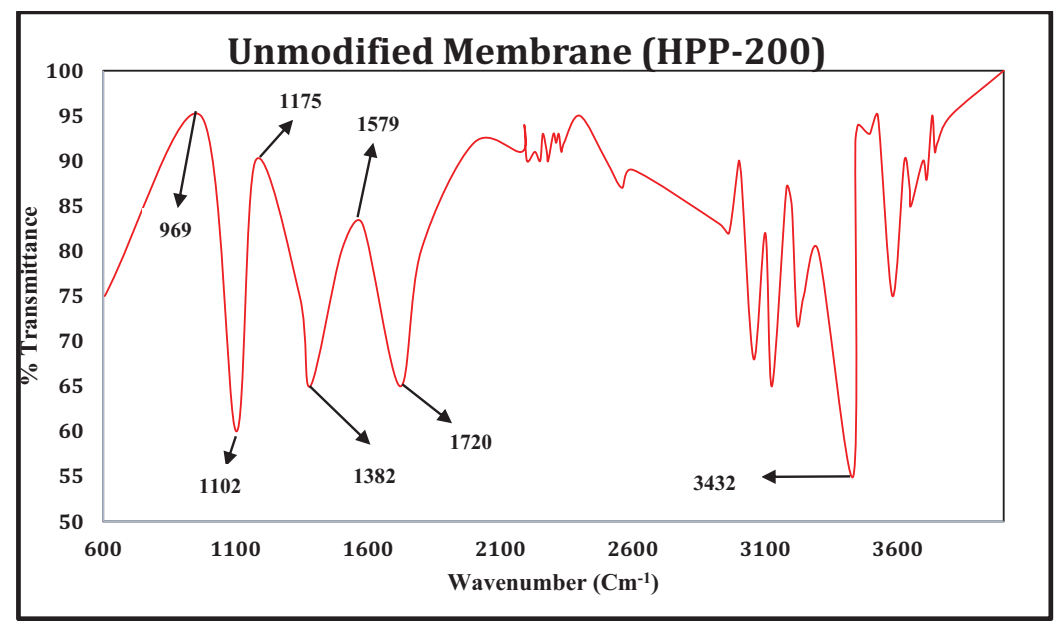

Fig (16). FTIR of Unmodified Membrane (HPP-200). 


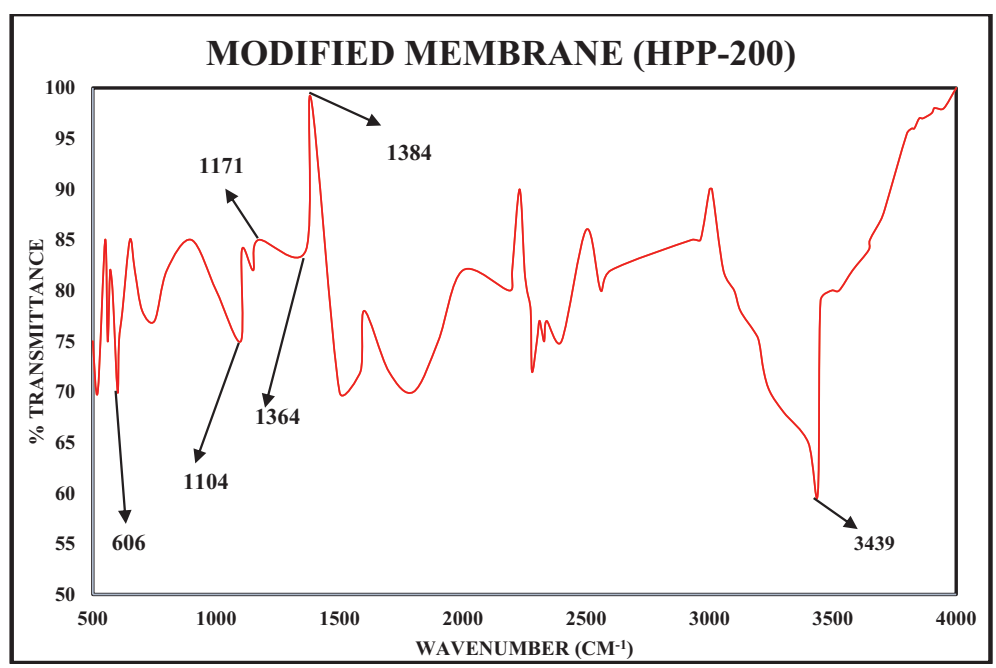

Fig (17). FTIR of Modified Membrane (HPP-200).

The stretching and vibrations are due to the interactions of the membrane with the $\mathrm{NaOH}$ in the feed. Though much change is not observed in the membrane properties, some variations in stretching and bending of certain bonds are observed which is the result of interactions of the solution components with the membrane.

\section{CONCLUSION}

New PVDF/PAN blend-based ultrafiltration membranes were synthesized by phase inversion method. The blend membrane was treated at room temperature with aqueous sodium hydroxide solutions. For separation of emulsified oily wastewater, the as-prepared composite (PVDF/PAN) membrane could effectively separate oil/ water emulsions with separation efficiency of above $99.8 \%$. Unmodified membranes (A and B) showed $95.4-99.8 \%$ rejection. However, in the case of membranes $\mathrm{C}$ and $\mathrm{D}$, oil rejection was higher for the modified membranes as compared to the unmodified membranes. These differences in the oil rejection strongly indicate that the oil rejection depends not only on the modification but also on the concentration of PVDF in the unmodified membrane. Oil rejection was increased with the increase in applied pressure. ATR-IR Spectra depicts the absorption of PVDF and PAN at band range 1000-1300 $\mathrm{cm}^{-1}$ and nearby $2250-2260 \mathrm{~cm}^{-1}$ on the modified membrane FTIR spectra confirm the $\mathrm{C}-\mathrm{C}$ band and $\mathrm{C}-\mathrm{C}-\mathrm{C}$ asymmetric stretching vibration band of PVDF were observed at 1171 and $889 \mathrm{~cm}^{-1}$, respectively while PAN corresponds the characteristic absorption peaks of nitrile $(-\mathrm{C} \mathrm{N})$ group at around $2240 \mathrm{~cm}^{-1}$ and $\left(\mathrm{CH}_{2}\right)$ group at $1390 \mathrm{~cm}^{-1}$. Therefore, the facile eco-friendly preparation of PVDF/PAN blended membrane has a potential for practical applications in emulsified wastewater remediation.

\section{NOMENCLATURE}

$\begin{array}{lll}\text { PVDF } & = & \text { Polyvinylidene difluoride } \\ \text { PAN } & = & \text { Polyacrylonitrile } \\ \text { PVP } & = & \text { Polyvinylpyrrolidone } \\ \text { NMP } & = & \text { N-methyl-2-pyrrolidone }\end{array}$

$\begin{array}{lll}\text { PEG } & = & \text { Polyethylene glycol } \\ \text { UF } & = & \text { Ultrafiltration } \\ \text { MF } & = & \text { Microfiltration } \\ \text { NF } & = & \text { Nanofiltration } \\ \text { RO } & = & \text { Reverse Osmosis }\end{array}$

\section{CONSENT FOR PUBLICATION}

Not applicable.

\section{AVAILABILITY OF DATA AND MATERIALS}

The authors confirm that the data supporting the findings of this study are available within the article.

\section{FUNDING}

This work was financially supported by Department of Chemical Engineering, P. P. Savani University as a part of inhouse research work.

\section{CONFLICT OF INTEREST}

The authors declare no conflict of interest, financial or otherwise.

\section{ACKNOWLEDGEMENTS}

We are grateful to the P P Savani University management for providing the research facility of membrane casting unit as well as permino membrane set-up throughout the experiment.

\section{REFERENCES}

[1] J. Dai, Z. Chang, A. Xie, R. Zhang, S. Tian, W. Ge, Y. Yan, C. Li, W. $\mathrm{Xu}$, and R. Shao, "One-step assembly of Fe(III)-CMC chelate hydrogel onto nanoneedle-like $\mathrm{CuO} @ \mathrm{Cu}$ membrane with superhydrophilicity for oil-water separation", Appl. Surf. Sci., vol. 440, pp. 560-569, 2018. [http://dx.doi.org/10.1016/j.apsusc.2018.01.213]

[2] P. Kajitvichyanukul, Y.T. Hung, and L.K. Wang, Membrane technologies for oil-water separation., Springer: Berlin, 2011, pp. 639-668.

[3] B. Dubansky, A. Whitehead, J.T. Miller, C.D. Rice, and F. Galvez, "Multitissue molecular, genomic, and developmental effects of the deepwater horizon oil spill on resident gulf killifish (Fundulus grandis)", Environ. Sci. Technol., vol. 47, pp. 5074-5082, 2013. [http://dx.doi.org/10.1021/es400458p] 
[4] N. Diban, A.T. Aguayo, J. Bilbao, A. Urtiaga, and I. Ortiz, "Membrane reactors for in situ water removal: A review of applications", Ind. Eng. Chem. Res., vol. 52, pp. 10342-10354, 2013.

[http://dx.doi.org/10.1021/ie3029625]

[5] A. Xie, J. Dai, C. Ma, J. Cui, Y. Chen, J. Lang, M. Gao, C. Li, and Y. Yan, "Construction of caterpillar-like cobalt-nickel hydroxide/carbon cloth hierarchical architecture with reversible wettability towards ondemand oil-water separation", Appl. Surf. Sci., vol. 462, pp. 659-668, 2018.

[http://dx.doi.org/10.1016/j.apsusc.2018.08.161]

[6] J. Coca, G. Gutie'rrez, and J. Benito, Treatment of oily wastewater by membrane hybrid processes., Springer: Dordrecht, 2013, pp. 35-61.

[7] G. Kwon, A.K. Kota, Y. Li, A. Sohani, J.M. Mabry, and A. Tuteja, "On-demand separation of oil-water mixtures", Adv. Mater., vol. 24, pp. 3666-3671, 2012 [http://dx.doi.org/10.1002/adma.201201364]

[8] Y. Peng, and Z. Guo, "Recent advances in biomimetic thin membranes applied in emulsified oil/water separation", J. Mater. Chem. A Mater. Energy Sustain., vol. 4, pp. 15749-15770, 2016.

[http://dx.doi.org/10.1039/C6TA06922C]

[9] C. Zhou, J. Cheng, K. Hou, A. Zhao, P. Pi, X. Wen, and S. Xu, "Superhydrophilic and underwater superoleophobic titania nanowires surface for oil repellency and oil/water separation", Chem. Eng. J., vol. 301, pp. 249-256, 2016

[http://dx.doi.org/10.1016/j.cej.2016.05.026]

[10] Y. Cao, N. Liu, W. Zhang, L. Feng, and Y. Wei, "One-step coating toward multifunctional applications: Oil/water mixtures and emulsions separation and contaminants adsorption", ACS Appl. Mater. Interfaces, vol. 8 , pp. $3333-3339,2016$

[http://dx.doi.org/10.1021/acsami.5b11226]

[11] Z. Chu, and S. Seeger, "Multifunctional hybrid porous micro/nanocomposite materials", Adv. Mater., vol. 27, p. 7775, 2015.

[http://dx.doi.org/10.1002/adma.201503502]

[12] L. Chen, Y. Wu, H. Dong, M. Meng, C. Li, Y. Yan, and J. Chen, "An overview on membrane strategies for rare earths extraction and separation", Separ. Purif. Tech., vol. 197, pp. 70-85, 2018. [http://dx.doi.org/10.1016/j.seppur.2017.12.053]

[13] G. Pearce, "Introduction to membranes: Membrane selection", Filtr. Sep., vol. 44, pp. 35-37, 2007.

[http://dx.doi.org/10.1016/S0015-1882(07)70083-6]

[14] Q.Y. Wu, L.S. Wan, and Z.K. Xu, "Centimeter-scale giant spherulites in mixtures of polar polymers and crystallisable diluents: Morphology, structure, formation and application", RSC Advances, vol. 3, pp. 17105-17112, 2013

[http://dx.doi.org/10.1039/c3ra41034j]

[15] J.F. Kim, J.T. Jung, H.H. Wang, S.Y. Lee, T. Moore, A. Sanguineti, E. Drioli, and Y.M. Lee, "Microporous PVDF membranes via thermally induced phase separation (TIPS) and stretching methods", J. Membr. Sci., vol. 509, pp. 94-104, 2016.

[http://dx.doi.org/10.1016/j.memsci.2016.02.050]

[16] J. Cui, Z. Zhou, A. Xie, Q. Wang, S. Liu, J. Lang, Y. Yan, and J. Dai,
"Facile preparation of grass-like structured NiCoJ Mater Sci (2019) 54:8332-8345 8343 LDH-PVDF composite membrane for efficient oil-water emulsion separation", J. Membr. Sci., vol. 573, pp. 226-233, 2019.

[http://dx.doi.org/10.1016/j.memsci.2018.11.064]

[17] Z.P. Zhao, Z. Wang, and S.C. Wang, "Formation, charged characteristic and BSA adsorption behavior of carboxymethyl chitosan/PES composite MF membrane", J. Membr. Sci., vol. 217, pp. 151-158, 2003.

[http://dx.doi.org/10.1016/S0376-7388(03)00105-4]

[18] Y. Gao, Z. Li, B. Cheng, and K. Su, "Superhydrophilic poly(pphenylene sulfide) membrane preparation with acid/ alkali solution resistance and its usage in oil/water separation", Separ. Purif. Tech., vol. 192, pp. 262-270, 2018.

[http://dx.doi.org/10.1016/j.seppur.2017.09.065]

[19] A.W. Zularisam, A.F. Ismail, and M.R. Salim, "Fabrication, fouling and foulant analyses of asymmetric polysulfone (PSF) ultrafiltration membrane fouled with Natural Organic Matter (NOM) source waters", J. Membr. Sci., vol. 299, pp. 97-113, 2007.

[http://dx.doi.org/10.1016/j.memsci.2007.04.030]

[20] Z. Cao, T. Hao, P. Wang, Y. Zhang, B. Cheng, T. Yuan, and J. Meng, "Surface modified glass fiber membranes with superior chemical and thermal resistance for O/W separation", Chem. Eng. J., vol. 309, pp. 30-40, 2017.

[http://dx.doi.org/10.1016/j.cej.2016.10.013]

[21] P.H.H. Duong, S.P. Nunes, and T.S. Chung, "Dual-skinned polyamide/poly(vinylidene fluoride)/cellulose acetate membranes with embedded woven", J. Membr. Sci., vol. 520, pp. 840-849, 2016. [http://dx.doi.org/10.1016/j.memsci.2016.08.047]

[22] S. Hu, L. Yu, J. Yin, H. Wang, X. Yuan, and Q. Li, "Effect of different binders on electrochemical properties of $\mathrm{LiFePO} / \mathrm{C}$ cathode material in lithium ion batteries", Chem. Eng. J., vol. 237, pp. 497-502, 2014. [http://dx.doi.org/10.1016/j.cej.2013.08.119]

[23] J.P. Mehta, "Improvement of permeate flux by laboratory scale techniques in membrane separation processes", J. Mod. Chem. Chemi. Tech., vol. 10, no. 1, pp. 21-27, 2019.

[24] J.P. Mehta, "Flow Reversal and Pressure pulsation: Innovative technique to enhance flux in Nanofiltration", Emerg. Trends. Chemi. Eng., vol. 6, no. 3, pp. 1-7, 2019.

[25] J.P. Mehta, T.M. Patel, and K. Nath, "Investigating study on flux enhancement techniques in a Nanofiltration pilot plant-An Experimental overview", Int. J. Chem. Sep. Tech., vol. 4, no. 2, pp. 27-34, 2018.

[26] L.L. Coelho, M. Di Luccio, D. Hotza, R.D.F.P.M. Moreira, A.C. Moreira, C.P. Fernandes, K. Rezwan, and M. Wilhelm, "Tailoring asymmetric $\mathrm{Al} 2 \mathrm{O} 3$ membranes by combining tape casting and phase inversion", J. Memb. Sci., vol. 623, p. 119056.

[27] J. Mehta, D.S. Panwar, S. Ghardesia, A. Chauhan, V.V. Atodariya, B. Banerjee, A. Metre, and M.S. Bhakhar, "Drying of banana-stepwise effect in drying air temperature on drying kinetics", Open Chem. Eng. $J$., vol. 14 , no. 1,2020 [http://dx.doi.org/10.2174/1874123102014010071]

\section{(C) 2021 Mehta et al.}

This is an open access article distributed under the terms of the Creative Commons Attribution 4.0 International Public License (CC-BY 4.0), a copy of which is available at: https://creativecommons.org/licenses/by/4.0/legalcode. This license permits unrestricted use, distribution, and reproduction in any medium, provided the original author and source are credited. 